\title{
A multiphase nickel iron sulfide hybrid electrode for highly active oxygen evolution
}

\author{
Pengsong $\mathrm{Li}^{\dagger}$, Xiuping $\mathrm{Zhao}^{\dagger}$, Xinxuan Duan, Yaping $\mathrm{Li}^{*}$, Yun Kuang ${ }^{*}$ and Xiaoming Sun
}

\begin{abstract}
Development of highly active electrocatalysts for oxygen evolution reaction (OER) is one of the critical issues for water splitting, and most reported catalysts operate at overpotentials above $190 \mathrm{mV}$. Here we present a multiphase nickel iron sulfide (MPS) hybrid electrode with a hierarchical structure of iron doped $\mathrm{NiS}$ and $\mathrm{Ni}_{3} \mathrm{~S}_{2}$, possessing a benchmark OER activity in alkaline media with a potential as low as $1.33 \mathrm{~V}$ (vs. reversible hydrogen electrode) to drive an OER current density of $10 \mathrm{~mA} \mathrm{~cm}$. The Fe doped NiS, combined with highly conductive disulfide phase on porous $\mathrm{Ni}$ foam, is believed to be responsible for the ultrahigh activity. Furthermore, density functional theory simulation reveals that partially oxidized sulfur sites in Fe doped NiS could dramatically lower the energy barrier for the rate-determining elementary reaction, thus contributing to the active oxygen evolution.
\end{abstract}

Keywords: multiphase, nickel iron sulfide, topotactic conversion, oxygen evolution reaction

\section{INTRODUCTION}

Hydrogen, with high gravimetric energy density, is considered as one of the most promising clean energy carriers [1]. Large-scale electrolysis of water to produce clean hydrogen fuel offers a sustainable and efficient approach for the renewable energy storage $[2,3]$. The electrocatalytic water splitting consists of two half-cell reactions, hydrogen evolution reaction (HER) and oxygen evolution reaction (OER) $[4,5]$. In the past several years, great progress has been made on the HER side for the advancement of cost effective catalysts [6,7]. Earth abundant materials have been widely used for highly active and stable electrocatalytic hydrogen generation [8,9]. However, the OER catalyst requires several-fold higher overpotential than HER catalyst to trigger the oxygen generation so far $[10,11]$, mainly because OER is a four- electron transfer process with many complex intermediates, resulting in extreme difficulty in finding a catalyst that offers suitable adsorption/desorption sites to all the intermediates, thus making OER kinetically sluggish [12]. Even with highly expensive precious metalbased catalysts, such as $\mathrm{IrO}_{2}$ and $\mathrm{RuO}_{2}$, a substantial overpotential $(\sim 300 \mathrm{mV})$ is still required to drive an OER current density of $10 \mathrm{~mA} \mathrm{~cm}{ }^{-2}$, a widely used figure of merit equivalent to $\sim 12 \%$ solar to hydrogen efficiency $[13,14]$. Such $300 \mathrm{mV}$ overpotential would result in energy loss during electrolysis, leading to high electrical power consumption, which is unacceptable for grid scale electrolysis.

Aiming to lower the operating overpotential, great efforts have been devoted to OER catalyst design [15]. Due to the oxygen involved reaction mechanism, oxide/hydroxide is the first choice as OER catalysts [16]. Among various progresses, Ni, Co, Fe based catalysts show much improved activity, but a significant overpotential is still required for the state-of-the-art catalysts $[17,18]$. Very recently, theoretical simulation indicated that there existed a $\sim 200 \mathrm{mV}$ overpotential limit for first-row (3d) transition metal oxide based OER catalyst due to a constant energy barrier between the $2^{\text {nd }}$ step intermediates and the final state of the catalyst [19]. To breaking such scaling law, non-3d high-valency metals (such as W) doped Co, Fe based catalysts show further improved OER activity through near-optimal ${ }^{\star} \mathrm{OH}$ energetics for OER [20], but a $\sim 190 \mathrm{mV}$ overpotential is still required. Transitional metal doping could tune the electronic structure of the positive metal sites [21], while anion exchange from oxide or hydroxide to $\mathrm{S}, \mathrm{P}$ or Se containing metal compounds [22,23], provides other choices for OER catalyst design because it could also tune the surface electronic structure of the negative non-metal

State Key Laboratory of Chemical Resource Engineering, College of Chemistry, Beijing Advanced Innovation Center for Soft Matter Science and Engineering, Beijing University of Chemical Technology, Beijing 100029, China

${ }^{\dagger}$ These authors contributed equally to this paper.

* Corresponding authors (emails: sunxm@mail.buct.edu.cn (Sun X); kuangyun@mail.buct.edu.cn (Kuang Y); liyp@mail.buct.edu.cn (Li Y)) 
sites [24]. For instance, $\mathrm{NiFe}$ selenide [25], $\mathrm{Ni}_{3} \mathrm{~S}_{2}$ [26], $\mathrm{NiFeS}_{2}$ [27] derived oxyhydroxide catalysts show overpotentials about $190 \mathrm{mV}$. Other methods including phosphorization [28-30] also show improved activity, providing the possibilities to break the energy barrier limit $(\sim 200 \mathrm{mV})$.

Herein, we report a multiphase nickel iron sulfide (MPS) electrode with partial surface oxidation can lower the OER operating overpotential down to $100 \mathrm{mV}$ level. The electrode was prepared by sulfuration of NiFe-LDH (layered double hydroxide) array on $\mathrm{Ni}$ foam substrate, resulting in a hierarchical iron doped $\mathrm{NiS}$ and $\mathrm{Ni}_{3} \mathrm{~S}_{2}$ structure. The synergistic effects between the multiphase sulfides, combined with highly conductive $\mathrm{Ni}_{3} \mathrm{~S}_{2}$ phase on porous $\mathrm{Ni}$ foam, are believed to be responsible for the ultrahigh activity; meanwhile, theoretical simulation suggests that partially oxidized sulfur sites in $(\mathrm{Ni}, \mathrm{Fe}) \mathrm{S}$ contributes most to the active electrolysis by lowering the energy barrier of the OER intermediates dramatically.

\section{EXPERIMENTAL SECTION}

\section{Chemicals}

All the reagents were of analytical grade and used as received without further purification. Ni foam was purchased from China National Pharmaceutical Industry Corporation Ltd.

Synthesis of NiFe-LDH array, the sulfide nanosheets array and the $\mathrm{Ni}_{3} \mathrm{~S}_{2}$ on $\mathrm{Ni}$ foam

$\mathrm{NiFe}-\mathrm{LDH}$ nanosheets array on $\mathrm{Ni}$ foam $(\mathrm{NiFe}-\mathrm{LDH} / \mathrm{NF})$ was synthesized by a simple hydrothermal method [31]. In a typical procedure, $\mathrm{Ni}\left(\mathrm{NO}_{3}\right)_{2} \cdot 6 \mathrm{H}_{2} \mathrm{O}(0.67 \mathrm{mmol})$, $\mathrm{Fe}\left(\mathrm{NO}_{3}\right)_{3} \cdot 9 \mathrm{H}_{2} \mathrm{O}(0.33 \mathrm{mmol})$ and $\mathrm{CO}\left(\mathrm{NH}_{2}\right)_{2}(5 \mathrm{mmol})$ were dissolved in $35-38 \mathrm{~mL}$ of distilled water and stirred to form a clear solution. Nickel foam (about $3 \mathrm{~cm} \times 4 \mathrm{~cm}$ ) was carefully cleaned with concentrated $\mathrm{HCl}$ solution (37 wt\%) in an ultrasound bath for $5 \mathrm{~min}$ in order to remove the surface $\mathrm{NiO}$ layer, and then deionized water and absolute ethanol were used for $3 \mathrm{~min}$ each to ensure the surface of the nickel foam well cleaned. The aqueous solution and nickel foam was transferred to a $40-\mathrm{mL}$ Teflon-lined stainless-steel autoclave, which was sealed, maintained at $120^{\circ} \mathrm{C}$ for $12 \mathrm{~h}$, and then allowed to cool to room temperature naturally. A brown thin film on the metal substrate formed and subsequently was rinsed with distilled water and ethanol each for $5 \mathrm{~min}$ with the assistance of ultrasonication and dried at $80^{\circ} \mathrm{C}$ for $6 \mathrm{~h}$. We got the approximate NiFe-LDH mass $\left(2.7 \mathrm{mg} \mathrm{cm}{ }^{-2}\right)$ by comparing the mass weighed before and after the reac- tion.

Synthesis of the MPS array on Ni foam by topotactic conversion through solution reaction. In a typical procedure, $\mathrm{CS}_{2}(35 \mathrm{~mL})$ and sulfur $(0.1 \mathrm{~g})$ were put into a 40-mL Teflon-lined stainless-steel autoclave and stirred until a clear solution was formed. Then NiFe-LDH/NF films were transferred to the Teflon-lined stainless-steel autoclave, maintained at $120^{\circ} \mathrm{C}$ for $24 \mathrm{~h}$. The post treatment of sulfides nanosheets array was similar to those of $\mathrm{NiFe}-\mathrm{LDH} / \mathrm{NF}$. Finally, we got the MPS nanosheets array from $\mathrm{NiFe}-\mathrm{LDH}$ array in $\mathrm{Ni}$ foam, and the approximate active material mass $\left(5 \mathrm{mg} \mathrm{cm}^{-2}\right)$ of MPS was obtained by comparing the mass weighed before and after the reaction.

Synthesis of the $\mathrm{Ni}_{3} \mathrm{~S}_{2}$ on Ni foam was almost same with that for MPS nanosheets array, except for NiFe-LDH/NF precursor replaced by $\mathrm{Ni}$ foam with clean surface.

\section{Materials characterization}

The size and morphology of the samples were characterized using a field-emission scanning electron microscope (SEM) (JEOL JSM6335) operated at $20 \mathrm{kV}$. High-resolution transmission electron microscopy (HRTEM) measurements were carried out using a JEOL JEM 2100 system operating at $200 \mathrm{kV}$. X-ray powder diffraction (XRD) patterns were recorded on an X-ray diffractometer (Rigaku $\mathrm{D} / \max 2500$ ) with $\mathrm{Cu} \mathrm{Ka}$ radiation $(40 \mathrm{kV}, 30 \mathrm{~mA}, \lambda=1.5418 \AA)$ at a scan rate of $10^{\circ} \mathrm{min}^{-1}$ in the $2 \theta$ range from $10^{\circ}$ to $70^{\circ}$. X-ray photoelectron spectra (XPS) were carried out by using a model of ESCALAB 250 and LabRAM Aramis.

\section{Electrochemical measurements}

The electrochemical measurements were carried out at room temperature in a three-electrode glass cell connected to an electrochemical workstation (CHI 660e, Chenghua, Shanghai). The nanosheets array on the nickel foam substrate $(1 \mathrm{~cm} \times 1 \mathrm{~cm})$ was used as working electrode. A carbon rod and a saturated calomel electrode (SCE) were used as the counter and reference electrodes, respectively. The $\mathrm{IrO}_{2} / \mathrm{C} / \mathrm{NF}$ electrode was prepared by the following procedure. First, $10 \mathrm{mg}$ of $\mathrm{IrO}_{2} / \mathrm{C}$ and $10 \mu \mathrm{L}$ of $5 \mathrm{wt} \%$ nafion solution were dispersed in ethanol $(990 \mu \mathrm{L})$ with the assistance of ultrasonication for at least $1 \mathrm{~h}$ to form a homogeneous catalyst ink. Then $500 \mathrm{uL}$ of the catalyst ink was dropped onto the $\mathrm{Ni}$ foam $(1 \mathrm{~cm} \times$ $1 \mathrm{~cm}$ ) under an infrared radiation (IR) lamp. A freshly prepared $1.0 \mathrm{~mol} \mathrm{~L}^{-1} \mathrm{KOH}$ aqueous solution was used as the electrolyte. The electrolyte was saturated by oxygen bubbles before and during the experiments. Polarization 
curves were obtained using linear sweep voltammetry (LSV) with a scan rate of $1 \mathrm{mV} \mathrm{s}^{-1}$. All polarization curves were corrected for an ohmic drop tested by impedance spectroscopy. The current density was normalized to the geometrical surface area. The measured potentials $v s$. SCE were converted to a reversible hydrogen electrode (RHE) scale according to the Nernst equation $\left(E_{\mathrm{RHE}}=E_{\mathrm{SCE}}+0.2415\right.$ $+0.0591 \mathrm{pH}$ ), where $0.2415 \mathrm{~V}$ was the standard potential of SCE. The electrochemical impedance spectroscopy (EIS) was obtained by alternating current (AC) impedance spectroscopy in $1.0 \mathrm{~mol} \mathrm{~L}^{-1} \mathrm{KOH}$ solution at open circuit voltage from $10^{5}$ to $0.1 \mathrm{~Hz}$ with an AC voltage of $5 \mathrm{mV}$ to measure the system resistance.

\section{Theoretical calculation}

All density functional theory (DFT) calculations were carried out by Vienna ab-Initio Simulation Package (VASP). The projector augmented wave pseudopotentials method was used for describing electron-ion interactions $[32,33]$. The Perdew-Burke-Ernzerh (PBE) exchange correlation functional with the on-site Coulomb Repulsion $U$ term was used [34]. In the present work, $U=6.45$ for $\mathrm{Ni}$ transition metal and $U=5.30$ for $\mathrm{Fe}$ transition metal $[35,36]$. All the atom positions in the bulk sulfides were optimized by the conjugate-gradient optimization procedure. The Brillouin zone integrations were performed using a $3 \times 3 \times 3$ Monkhorst-Pack grids for the bulk. A spin-polarized approach was adopted. The kpoint sampling consists of $3 \times 3 \times 1$ Monkhorst-Pack points for all slab models. A vacuum of at least $16 \AA$ was adopted along $z$-axis. During structure optimization, all energies change criterion was set to $10^{-4} \mathrm{eV}$, the maximum force was $0.02 \mathrm{eV} \AA^{-1}$, and the plane wave cutoff was set to $400 \mathrm{eV}$.

\section{RESULTS AND DISCUSSION}

The MPS electrode was prepared through a two-step procedure (Fig. 1a). Firstly, NiFe-LDH nanosheets array was synthesized on the nickel foam substrate by our previous method [31]. Then, the as-formed NiFe-LDH nanoarrays were sulfurized to MPS by our newly devised solvothermal $S$ treatment method in carbon disulfide. SEM images of NiFe-LDH and MPS show similar 3D open porous structure with interconnected nanosheets (Fig. $1 \mathrm{~b}$ and c) growing vertically on the substrate, and the MPS electrode shows rough surfaces.

The morphology and crystalline structure of MPS were revealed by TEM. Fig. 1d shows a single piece of nanosheet sonicated off the electrode, revealing a $2 \mathrm{D}$ nanosheet morphology with rough surface. Selected area electron diffraction (SAED) pattern of the MPS nanosheet demonstrates a polycrystalline structure, which is different from the crystalline structure of $\mathrm{LDH}$ precursor (Fig. S1). Analysis of the SAED rings indicates a multiphase sulfides structure consisting of iron doped nickel monosulfide and disulfide. HRTEM image reveals a seaisland structure of the rough surface as evidenced by typical (300) and (110) lattice fringes of $\mathrm{NiS}$ and $\mathrm{Ni}_{3} \mathrm{~S}_{2}$ with
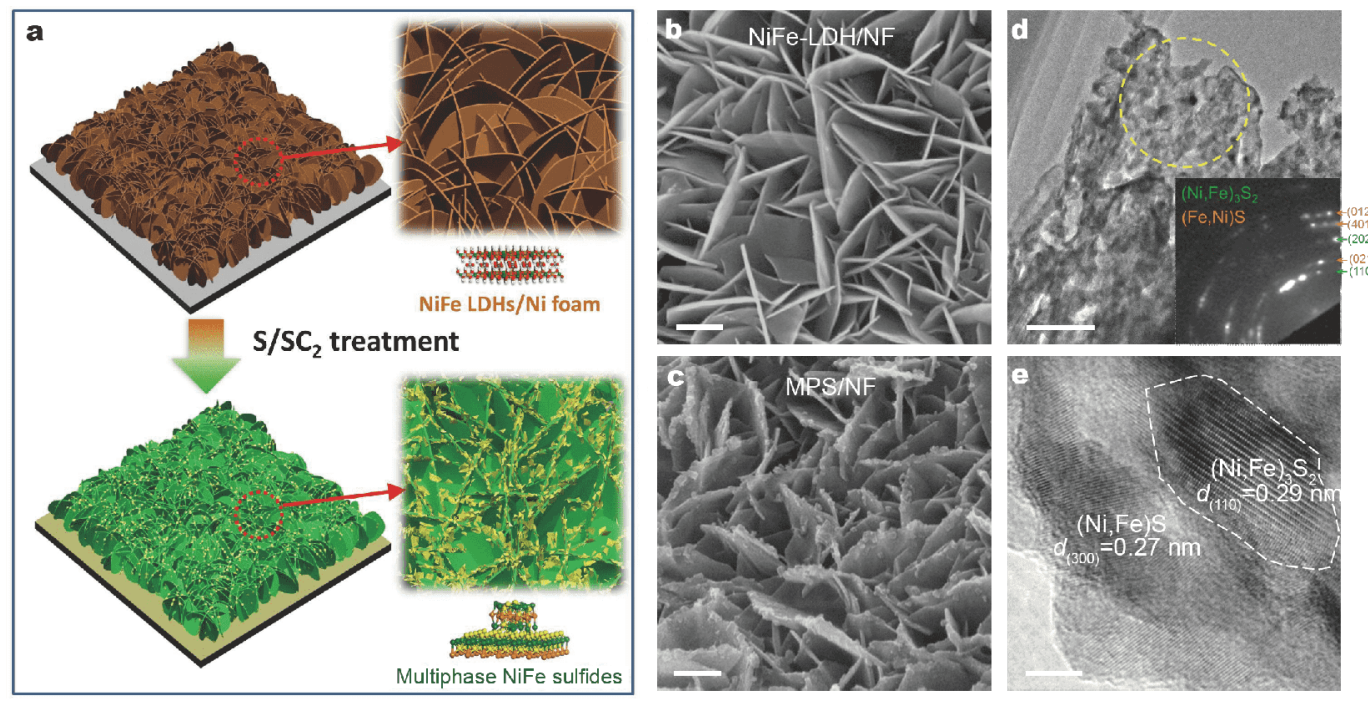

Figure 1 (a) Scheme of topotactic conversion from NiFe-LDH array to MPS array on Ni foam substrate. (b, c) SEM images of typical NiFe-LDH/NF and MPS/NF nanosheets array (scale bar is $200 \mathrm{~nm}$ ). (d) TEM image of a typical MPS nanosheet (scale bar is $100 \mathrm{~nm}$ ). Inset shows the electron diffraction pattern of the marked region. (e) HRTEM image of a MPS nanosheet, showing monosulfide and disulphide phases. Scale bar is $5 \mathrm{~nm}$. 
larger lattice spaces caused by Fe doping (Fig. 1e). Energy-dispersive X-ray spectrometry (EDS) elemental mapping of the MPS electrode shows uniformly distributed $\mathrm{Ni}, \mathrm{Fe}$ and $\mathrm{S}$ (Fig. S2), further evidencing Fe doping in nickel sulfide and disulfide. Moreover, the MPS electrode contains abundant oxygen (Fig. S3), resulting from the oxidation of the catalyst surface. The XRD patterns were employed to investigate the crystalline phase change during the in situ topotactic sulfuration process (Fig. 2a). The diffraction peaks of (003), (006), (012), (015), (110) and (113) were observed for the NiFeLDH precursor, while monosulfide (PDF\#12-0041) and disulphide (PDF\#44-1418) diffraction peaks could be found after in situ sulfuration and no LDH peak was observed, suggesting fully conversion to sulfides. Comparing the (111) peak intensities of nickel foam (marked as “*”) between the precursor and final product (Fig. S4), the intensity of NiFe-LDH/NF is 1.6 times that of MPS/ $\mathrm{NF}$, indicating the nickel foam is slightly sulfurized in the same sulfuration process. Control experiment without $\mathrm{LDH}$ on $\mathrm{Ni}$ foam surface indicates that the $\mathrm{Ni}$ foam is also sulfurized to $\mathrm{Ni}_{3} \mathrm{~S}_{2}$ (Fig. S5). However, $\mathrm{Ni}_{3} \mathrm{~S}_{2}$ (Fig. S5) is a conducting sulfide with $\mathrm{Ni}-\mathrm{Ni}$ bond in its crystal, and thus the sulfuration of the $\mathrm{Ni}$ foam would not influence actual electrochemical performance. XRD pattern (Fig. S6) of the sulfuration intermediates (reaction at 0,2, $4,8,12,18,24 \mathrm{~h}$ ) shows sulfur signal at the begging, while sulfides begin to appear after $4 \mathrm{~h}$ reaction, suggesting a sulfur adsorption-intercalation-sulfuration process.

The surface chemical composition and chemical states of MPSs were analyzed by XPS. Using the NiFe-LDH as the reference, all the Ni $2 p$, and Fe $2 p$ peaks were consistent with the characteristics of $\mathrm{Ni}^{2+}$ and $\mathrm{Fe}^{3+}$ in NiFeLDH. After topotactic conversion, the valence state of nickel changes significantly. The $\mathrm{Ni}^{2+}$ peak shifts to low energy region, suggesting the transformation from $\mathrm{Ni}-\mathrm{O}$ bond to $\mathrm{Ni}-\mathrm{S}$ bond. The appearance of a new $\mathrm{Ni}^{0}$ $(853.1 \mathrm{eV})$ peak evidences the formation of $\mathrm{Ni}-\mathrm{Ni}$ bonds, which comes from either the surface Fe doped $\mathrm{Ni}_{3} \mathrm{~S}_{2}$ or the bottom $\mathrm{Ni}_{3} \mathrm{~S}_{2} \cdot \mathrm{Fe}^{3+}$ peak of MPS also shifts to low energy region, possibly because of lower binding capacity of sulfur, and thus the metals would have higher electron cloud density around it. The O 1s spectra (Fig. S7) indicates there are abundant oxygen on the MPS surface,
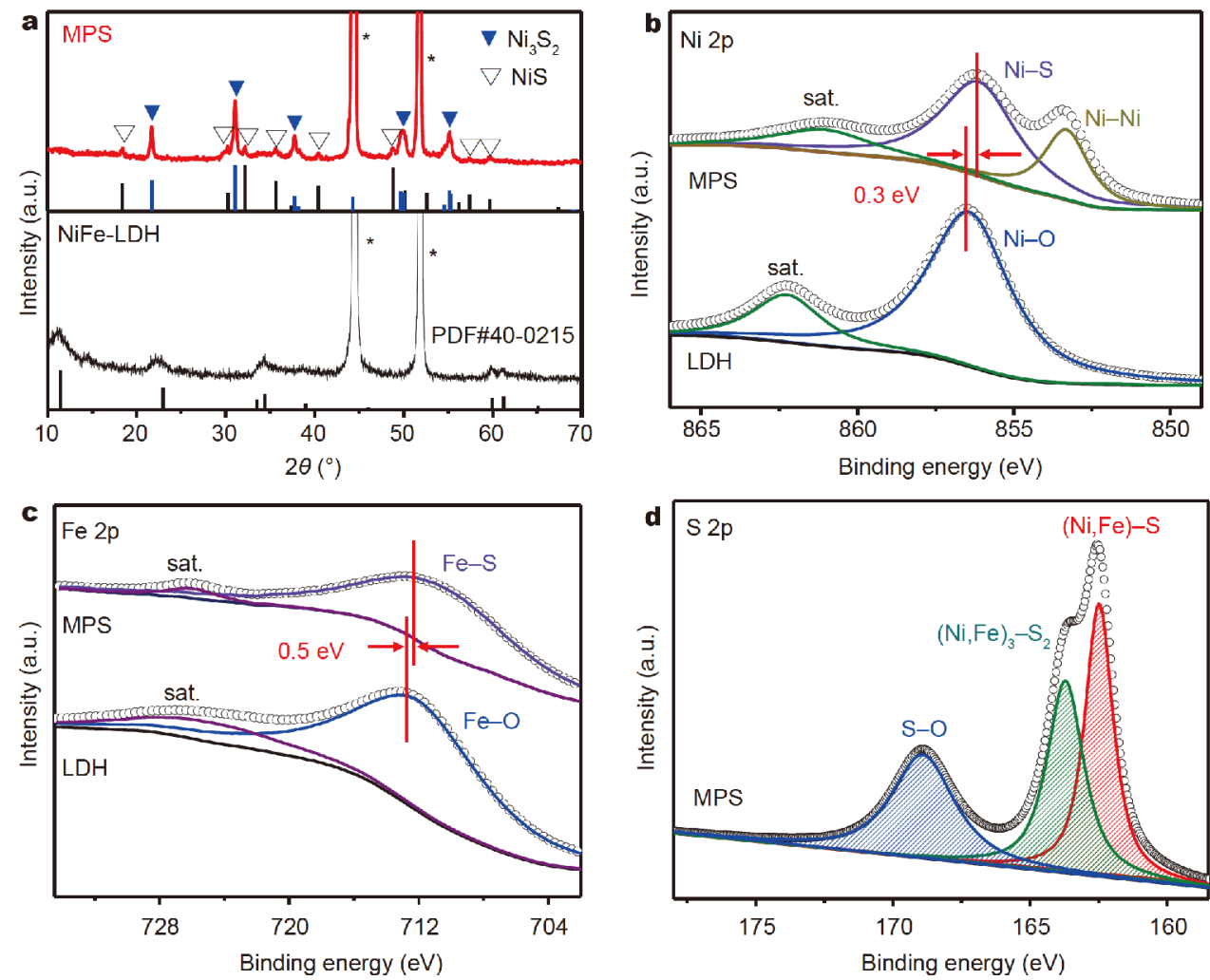

Figure 2 (a) XRD patterns of NiFe-LDH/NF and MPS/NF electrodes. XPS spectra of (b) Ni and (c) Fe in NiFe-LDH/NF and MPS/NF electrodes. (d) XPS spectra of $S$ in MPS/NF electrode. 
which is consistent with the previous EDS data. The highresolution $S 2 \mathrm{p}$ spectra could be convoluted into two peaks locating at 162.5 and $163.7 \mathrm{eV}$ (Fig. 2d) [37], assigned to valence states of $\mathrm{M}-\mathrm{S}$ and $\mathrm{M}_{3}-\mathrm{S}_{2}$ (the $\mathrm{M}$ stands for $\mathrm{Ni}$ or $\mathrm{Fe}$ ), further evidencing multiphase sulfides structure. The peak located at $169 \mathrm{eV}$ represents $\mathrm{S}=\mathrm{O}$ bond and the corresponding Raman vibrations of $\mathrm{S}=\mathrm{O}$ bond could be detected in Raman spectrum at 985 and $1050 \mathrm{~cm}^{-1}$ (Fig. S8), indicating that the $S$ element was partially oxidized in the MPS catalysts.

The electrocatalytic OER performance of MPS/NF electrode was evaluated in $1.0 \mathrm{~mol} \mathrm{~L}^{-1} \mathrm{KOH}$ solution using a typical three electrode configuration, in which a carbon rod and a SCE were used as the counter and reference electrodes, respectively. The activity of $\mathrm{Ni}$ foam, $\mathrm{Ni}$ foam-supported NiFe-LDH (NiFe-LDH/NF), and $\mathrm{IrO}_{2} / \mathrm{C}$ (Fig. S9) were also measured for comparison. OER polarization curves reveal that MPS/NF electrode exhibits a remarkable activity. To achieve a current density of $10 \mathrm{~mA} \mathrm{~cm}^{-2}$, the overpotential required for MPS/NF electrode is as low as $100 \mathrm{mV}$, which is much smaller than that of $\mathrm{NiFe}-\mathrm{LDH} / \mathrm{NF} \quad(230 \mathrm{mV})$ and $\mathrm{IrO}_{2} / \mathrm{C} / \mathrm{NF}$ $(310 \mathrm{mV})$ in the same current density (Fig. 3b). Actually, such a small overpotential of MPS/NF electrode is almost
$100 \mathrm{mV}$ lower than that of the state-of-the-art catalysts reported so far, suggesting a 1-2 magnitude higher OER activity (Table S1). The possible reason for such a high activity is fast electron transfer kinetics on MPS/NF electrode, evidenced by EIS in which a much smaller charge transfer resistance $\left(R_{\mathrm{c}}, 0.7 \Omega\right)$ is required for MPS/ $\mathrm{NF}$ electrode than that of $\mathrm{NiFe}-\mathrm{LDH} / \mathrm{NF}(1.6 \Omega)$ and $\mathrm{IrO}_{2} / \mathrm{C} / \mathrm{NF}(3.8 \Omega$ ) during the OER process (Fig. 3c). The MPS/NF also exhibits higher activity than that of the mixture of $\mathrm{NiS}$ and $\mathrm{Ni}_{3} \mathrm{~S}_{2}\left(\mathrm{NiS}_{x} / \mathrm{NF}\right.$, Fig. S10), indicating the iron doping can effectively promote the OER activity. The electrochemical double layer capacitances $\left(C_{\mathrm{dl}}\right)$ reveal the highest electrochemical surface area (ECSA) of MPS/ NF electrode $\left(16,370 \mu \mathrm{F} \mathrm{cm}{ }^{-2}\right.$, Fig. S11 and Fig. 3d), which is about 7 times higher than that of NiFe-LDH/NF $\left(2110 \mu \mathrm{F} \mathrm{cm}^{-2}\right)$, suggesting a much faster anion exchange ability between the electrolyte and catalytic active sites on MPS/NF electrode. The intrinsic activity of MPS/NF is higher than that of NiFe-LDH/NF (Fig. S12) when the current density normalized to the unit $C_{\mathrm{dl}}$. The single phase $(\mathrm{Ni}, \mathrm{Fe}) \mathrm{S}$ attaching on the surface of $\mathrm{Ni}$ foam was fabricated by ion exchange of NiFe-LDH/NF in the $\mathrm{Na}_{2} \mathrm{~S}$ solution. The MPS/NF electrode shows much higher activity than the pure (Ni,Fe)S array (Fig. S13), which might
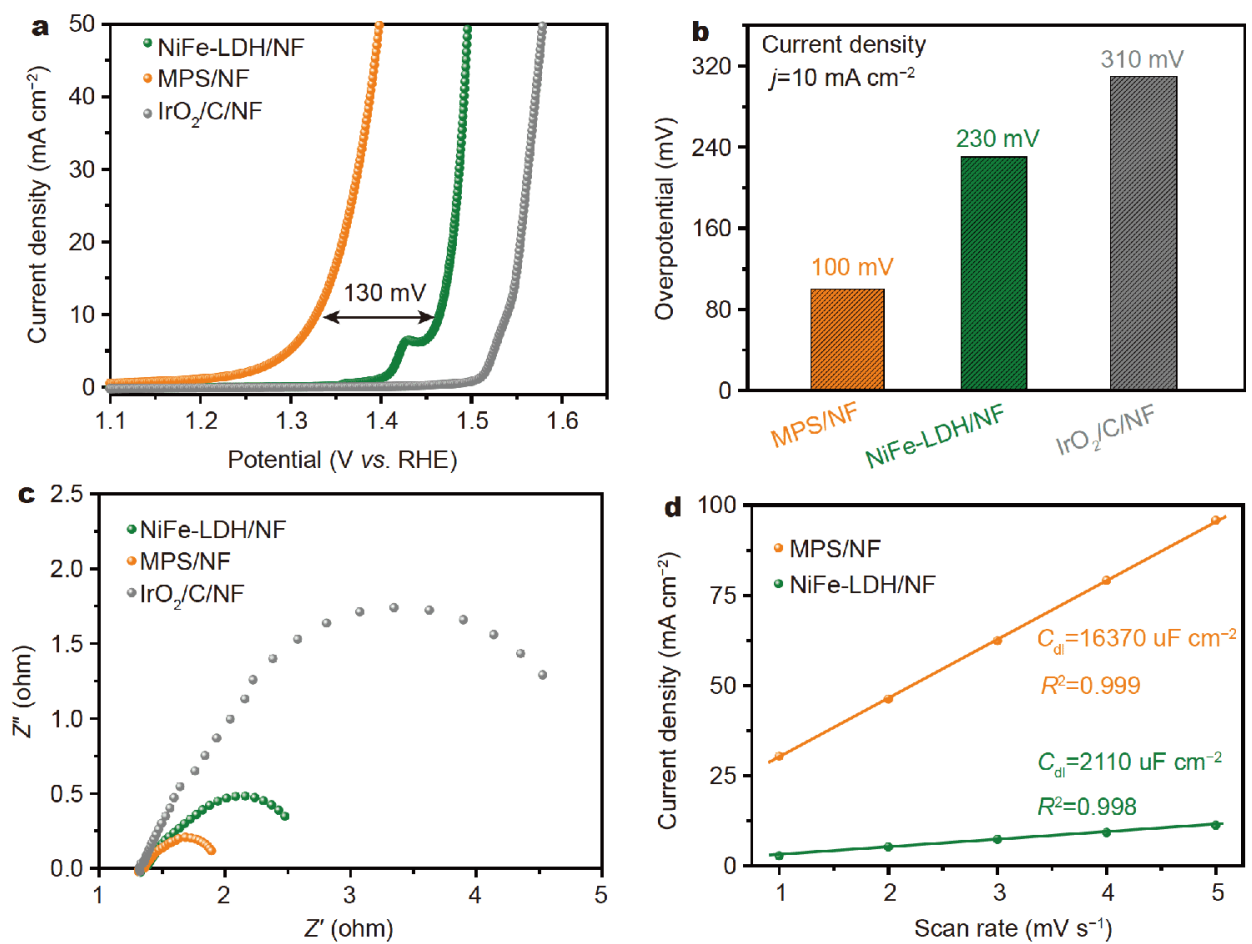

Figure 3 (a) OER performance and (b) comparison of OER overpotential at current density of $10 \mathrm{~mA} \mathrm{~cm}^{-2}$ for NiFe-LDH, MPS and IrO $/ 2$. (c) EIS of $\mathrm{NiFe}-\mathrm{LDH} / \mathrm{NF}, \mathrm{MPS} / \mathrm{NF}$ and $\mathrm{IrO}_{2} / \mathrm{C} / \mathrm{NF}$. (d) $C_{\mathrm{dl}}$ calculation of NiFe-LDH and MPS nanosheets array. All the tests were carried out in 1.0 mol $\mathrm{L}^{-1}$ $\mathrm{KOH}$ solution. 
be attributed to the sea/island multiphase structure. Notably, the electrode could work actively under a small current density ( $1 \mathrm{~mA} \mathrm{~cm}^{-2}$, Fig. S14), and high current density would cause irreversible activity loss (3 and $5 \mathrm{~mA} \mathrm{~cm}^{-2}$, Fig. S14), because high overpotential causes severe oxidation of the sulfide surface, which means that a suitable oxidation state on the surface of the catalyst could favor the high stable catalytic activity. In order to investigate what material plays the key role for such high OER activity, control experiment of single phase $\mathrm{Ni}_{3} \mathrm{~S}_{2}$ was done on the same Ni foam substrate. Unfortunately, the OER performance of $\mathrm{Ni}_{3} \mathrm{~S}_{2}$ is even worse than that of NiFe-LDH/NF (Fig. S9), and therefore, the monosulfide should be the active sites for OER. After the OER test, the MPS/NF still maintains the nanosheet array structure (Fig. S15a); however, the crystallinity of monosulfide deteriorates (Fig. S15b), which might be due to the formation of amorphous oxyhydroxide on the surface of the active species during the OER process.

To further understand the activity behavior of the asprepared catalysts, DFT $+U$ computations were applied to calculate the Gibbs free energy of coordinate elementary steps and overpotentials for MPS/NF electrode. $(\mathrm{Ni}, \mathrm{Fe})_{3} \mathrm{~S}_{2}$ and $(\mathrm{Ni}, \mathrm{Fe}) \mathrm{S}$ were chosen to be the active material (Figs S16 and S17). A Ni-Fe couple site was selected for iron doped nickel sulfides $(\mathrm{Ni}, \mathrm{Fe}) \mathrm{S}$ and nickel disulfides $(\mathrm{Ni}, \mathrm{Fe})_{3} \mathrm{~S}_{2}$. The Gibbs free energy was calculated under a $4 \mathrm{e}$-mechanism proposed by Norskov et al. [19]. Both $(\mathrm{Ni}, \mathrm{Fe})_{3} \mathrm{~S}_{2}$ and $(\mathrm{Ni}, \mathrm{Fe}) \mathrm{S}$ show the same rate determining step, namely, the deprotonation of surfaceadsorbed superoxide $\mathrm{OOH}$ species releasing $\mathrm{O}_{2}$ molecule. Gibbs free energy plots $v s$. OER coordinate steps under the different potentials $(U=0 \mathrm{~V}$ and $1.23 \mathrm{~V})$ reveal a low Gibbs free energy difference value for the rate determining step of $(\mathrm{Ni}, \mathrm{Fe}) \mathrm{S}$ sites $\left(\Delta G_{\mathrm{IV}}=1.77 \mathrm{eV}\right.$, Fig. S17), suggesting easy electron transfer during OER process, which means the $(\mathrm{Ni}, \mathrm{Fe}) \mathrm{S}$ has a higher activity than $(\mathrm{Ni}, \mathrm{Fe})_{3} \mathrm{~S}_{2}$ and the $(\mathrm{Ni}, \mathrm{Fe}) \mathrm{S}$ maybe act as the active center and the $(\mathrm{Ni}, \mathrm{Fe})_{3} \mathrm{~S}_{2}$ serves as the conductive network in the multiphase sulfides electrode, consistent with the previous electrochemical analysis. Furthermore, in order to uncover the influence of oxidation degree with the $S$ element in the catalyst, some deeper computational simulations were carried out (Fig. S18). Fig. 4a, b and Fig. S19 show the proposed OER pathway for $(\mathrm{Ni}, \mathrm{Fe}) \mathrm{S}$ structure with $25 \% \mathrm{~S}$ oxidized and the calculated OER free energy diagram on the $\mathrm{Ni}-\mathrm{Fe}$ couple site in the $(\mathrm{Ni}$, $\mathrm{Fe}) \mathrm{S}$ model with different amounts $(0 \%, 25 \%, 50 \%$ and $75 \%)$ of S oxidized. The rate determining step will move to the deprotonation of the surface-adsorbed $\mathrm{OH}$ on the active sites with $25 \% \mathrm{~S}$ oxidized, corresponding to the decrease of overpotential, and subsequently, the generation and deprotonation of superoxide $\mathrm{OOH}$ species will be accelerated, which reveals mild oxidation of S in MPS/ NF electrode favors the reducing of kinetic resistance for OER processes. With increasing degree of S oxidation, the kinetics will slow down with the rate determining step switching to the generation of superoxide $\mathrm{OOH}$ species (Fig. 4d and Fig. S19), and thereby, the MPS/NF electrode will have obvious activity loss after excess oxidation, which is consistent with the electrochemical stability test (Fig. S14). That is to say, the suitable oxide interface is important not only in metal catalysts but also in sulphides for electrocatalytic performance enhancement. However, the repeatability of MPS/NF activity is challenging because it is hard to control the oxidation degree of S during the electrochemical process.

\section{CONCLUSIONS}

In summary, we developed a multiphase sulfides elec-
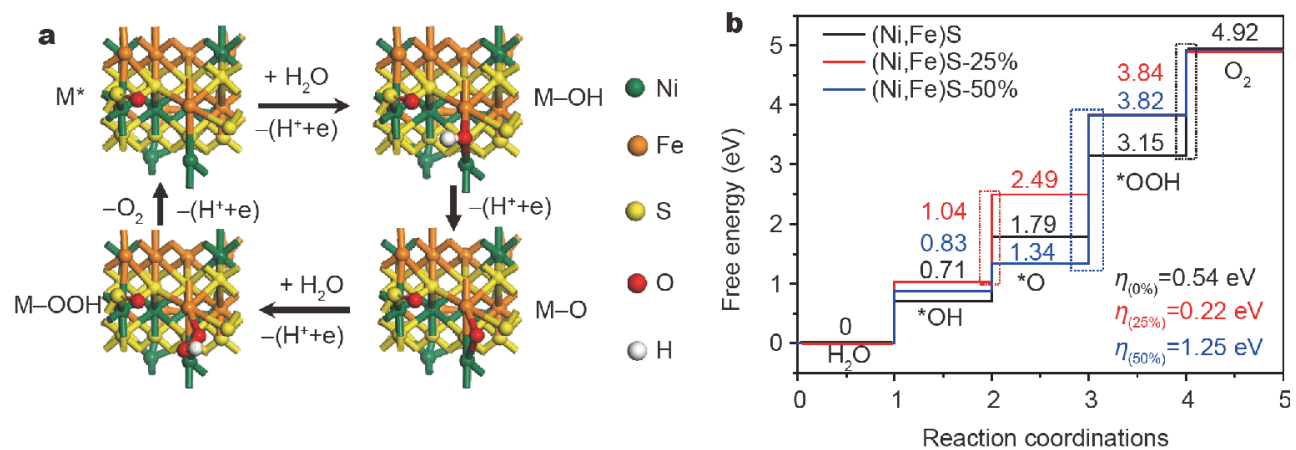

Figure 4 (a) Proposed OER pathway for (Ni,Fe)S structure with 25\% S oxidized with the Ni-Fe couple site as the active site. (b) The calculated OER free energy diagram on the Ni-Fe couple site in (Ni,Fe)S model with different amounts $(0 \%, 25 \%$ and $50 \%)$ of $\mathrm{S}$ oxidized. The $\eta$ stands for the overpotential of determining step (dotted box) and the lower free energy value suggests a higher OER intrinsic activity. 
trode for highly active OER. The MPS electrode afforded an extremely low overpotential $(\sim 100 \mathrm{mV})$ to achieve a current density of $10 \mathrm{~mA} \mathrm{~cm}$. The electrochemical analysis and DFT simulation reveal that partially oxidized sulfur in $(\mathrm{Ni}, \mathrm{Fe}) \mathrm{S}$ could dramatically lower the energy barrier for OER process combining with highly conductive network of $\mathrm{Ni}_{3} \mathrm{~S}_{2}$ phase. Such a highly active OER electrode provides an opportunity for grid-scale hydrogen generation with high energy efficiency.

\section{Received 30 August 2019; accepted 6 November 2019;} published online 20 November 2019

1 Turner JA. Sustainable hydrogen production. Science, 2004, 305: 972-974

2 Hu C, Zhang L, Gong J. Recent progress made in the mechanism comprehension and design of electrocatalysts for alkaline water splitting. Energy Environ Sci, 2019, 12: 2620-2645

3 Chandrasekaran S, Yao L, Deng L, et al. Recent advances in metal sulfides: From controlled fabrication to electrocatalytic, photocatalytic and photoelectrochemical water splitting and beyond. Chem Soc Rev, 2019, 48: 4178-4280

4 Li S, Hao X, Abudula A, et al. Nanostructured co-based bifunctional electrocatalysts for energy conversion and storage: Current status and perspectives. J Mater Chem A, 2019, 7: 18674-18707

5 Jiao Y, Zheng Y, Jaroniec M, et al. Design of electrocatalysts for oxygen- and hydrogen-involving energy conversion reactions. Chem Soc Rev, 2015, 44: 2060-2086

6 Shi Y, Zhang B. Recent advances in transition metal phosphide nanomaterials: Synthesis and applications in hydrogen evolution reaction. Chem Soc Rev, 2016, 45: 1529-1541

7 Li P, Duan X, Wang S, et al. Amorphous ruthenium-sulfide with isolated catalytic sites for Pt-like electrocatalytic hydrogen production over whole pH range. Small, 2019, 305: 1904043

8 Anantharaj S, Ede SR, Sakthikumar K, et al. Recent trends and perspectives in electrochemical water splitting with an emphasis on sulfide, selenide, and phosphide catalysts of $\mathrm{Fe}, \mathrm{Co}$, and $\mathrm{Ni}$ : A review. ACS Catal, 2016, 6: 8069-8097

9 Zheng Y, Jiao Y, Vasileff A, et al. The hydrogen evolution reaction in alkaline solution: From theory, single crystal models, to practical electrocatalysts. Angew Chem Int Ed, 2018, 57: 7568-7579

10 Fabbri E, Schmidt TJ. Oxygen evolution reaction-the enigma in water electrolysis. ACS Catal, 2018, 8: 9765-9774

11 Guo Y, Shang C, Li J, et al. Recent development of hydrogen evolution, oxygen evolution and oxygen reduction reaction. Sci Sin-Chim, 2018, 48: 926-940

12 Suen NT, Hung SF, Quan Q, et al. Electrocatalysis for the oxygen evolution reaction: Recent development and future perspectives. Chem Soc Rev, 2017, 46: 337-365

13 Reier T, Nong HN, Teschner D, et al. Electrocatalytic oxygen evolution reaction in acidic environments-reaction mechanisms and catalysts. Adv Energy Mater, 2017, 7: 1601275

14 Cherevko S, Geiger S, Kasian O, et al. Oxygen and hydrogen evolution reactions on $\mathrm{Ru}, \mathrm{RuO}_{2}$, $\mathrm{Ir}$, and $\mathrm{IrO}_{2}$ thin film electrodes in acidic and alkaline electrolytes: A comparative study on activity and stability. Catal Today, 2016, 262: 170-180

$15 \mathrm{Yu}$ F, Yu L, Mishra IK, et al. Recent developments in earthabundant and non-noble electrocatalysts for water electrolysis.
Mater Today Phys, 2018, 7: 121-138

16 Chen Y, Rui K, Zhu J, et al. Recent progress on nickel-based oxide/ (oxy)hydroxide electrocatalysts for the oxygen evolution reaction. Chem Eur J, 2019, 25: 703-713

17 Han L, Dong S, Wang E. Transition-metal (Co, Ni, and Fe)-based electrocatalysts for the water oxidation reaction. Adv Mater, 2016, 28: 9266-9291

18 Zhou P, He J, Zou Y, et al. Single-crystalline layered double hydroxides with rich defects and hierarchical structure by mild reduction for enhancing the oxygen evolution reaction. Sci China Chem, 2019, 62: 1365-1370

19 Rossmeisl J, Qu ZW, Zhu H, et al. Electrolysis of water on oxide surfaces. J Electroanal Chem, 2007, 607: 83-89

20 Zhang B, Zheng X, Voznyy O, et al. Homogeneously dispersed multimetal oxygen-evolving catalysts. Science, 2016, 352: 333-337

21 Li P, Duan X, Kuang Y, et al. Tuning electronic structure of NiFe layered double hydroxides with vanadium doping toward high efficient electrocatalytic water oxidation. Adv Energy Mater, 2018, 8: 1703341

22 Wang Y, Yan D, El Hankari S, et al. Recent progress on layered double hydroxides and their derivatives for electrocatalytic water splitting. Adv Sci, 2018, 5: 1800064

23 Zhou L, Shao M, Wei M, et al. Advances in efficient electrocatalysts based on layered double hydroxides and their derivatives. J Energy Chem, 2017, 26: 1094-1106

$24 \mathrm{Li}$ BQ, Zhang SY, Tang C, et al. Anionic regulated $\mathrm{NiFe}$ (oxy)sulfide electrocatalysts for water oxidation. Small, 2017, 13: 1700610

25 Du Y, Cheng G, Luo W. Colloidal synthesis of urchin-like Fe doped $\mathrm{NiSe}_{2}$ for efficient oxygen evolution. Nanoscale, 2017, 9: 6821-6825

26 Feng LL, Yu G, Wu Y, et al. High-index faceted $\mathrm{Ni}_{3} \mathrm{~S}_{2}$ nanosheet arrays as highly active and ultrastable electrocatalysts for water splitting. J Am Chem Soc, 2015, 137: 14023-14026

27 Dong B, Zhao X, Han GQ, et al. Two-step synthesis of binary $\mathrm{Ni}$-Fe sulfides supported on nickel foam as highly efficient electrocatalysts for the oxygen evolution reaction. J Mater Chem A, 2016, 4: 13499-13508

28 Li Y, Zhang $\mathrm{H}$, Jiang $\mathrm{M}$, et al. 3D self-supported Fe-doped $\mathrm{Ni}_{2} \mathrm{P}$ nanosheet arrays as bifunctional catalysts for overall water splitting. Adv Funct Mater, 2017, 27: 1702513

29 Gao WK, Yang M, Chi JQ, et al. In situ construction of surface defects of carbon-doped ternary cobalt-nickel-iron phosphide nanocubes for efficient overall water splitting. Sci China Mater, 2019, 62: $1285-1296$

30 Bai X, Ren Z, Du S, et al. In-situ structure reconstitution of $\mathrm{NiCo}_{2} \mathrm{P}$ for enhanced electrochemical water oxidation. Sci Bull, 2017, 62: $1510-1518$

31 Lu Z, Xu W, Zhu W, et al. Three-dimensional NiFe layered double hydroxide film for high-efficiency oxygen evolution reaction. Chem Commun, 2014, 50: 6479-6482

32 Kresse G, Hafner J. Ab initio molecular dynamics for liquid metals. Phys Rev B, 1993, 47: 558-561

33 Kresse G, Furthmüller J. Efficiency of ab-initio total energy calculations for metals and semiconductors using a plane-wave basis set. Comput Mater Sci, 1996, 6: 15-50

34 Hammer B, Hansen LB, Nørskov JK. Improved adsorption energetics within density-functional theory using revised perdewburke-ernzerhof functionals. Phys Rev B, 1999, 59: 7413-7421

35 Li P, Wang M, Duan X, et al. Boosting oxygen evolution of single- 
atomic ruthenium through electronic coupling with cobalt-iron layered double hydroxides. Nat Commun, 2019, 10: 1711

36 Xiong X, Cai Z, Zhou D, et al. A highly-efficient oxygen evolution electrode based on defective nickel-iron layered double hydroxide. Sci China Mater, 2018, 61: 939-947

37 Liao $\mathrm{Y}$, Pan $\mathrm{K}, \mathrm{Pan} \mathrm{Q}$, et al. In situ synthesis of a $\mathrm{NiS} / \mathrm{Ni}_{3} \mathrm{~S}_{2}$ nanorod composite array on $\mathrm{Ni}$ foil as a FTO-free counter electrode for dye-sensitized solar cells. Nanoscale, 2015, 7: 1623-1626

Acknowledgements This work was supported by the National Natural Science Foundation of China, the National Key Research and Development Project (2018YFB1502401), the Royal Society and Newton Fund through Newton Advanced Fellowship award (NAF\R1\191294), the Program for Changjiang Scholars and Innovative Research Team in the University, and the Fundamental Research Funds for the Central Universities, and the Longterm Subsidy Mechanism from the Ministry of Finance and the Ministry of Education of China. Li P thanks the financial support from China Scholarships Council (CSC).

Author contributions Li P, Sun X, and Kuang Y conceived the project and designed the experiments. Li P and Zhao X conducted the material synthesis and electrochemical measurements. Li P, Duan X, and Li Y carried out the theoretical calculations. Li P, Kuang Y and Sun X cowrote the paper. All authors discussed the results and commented on the manuscript.

Conflict of interest The authors declare no conflict of interest.

Supplementary information Supporting data are available in the online version of the paper.

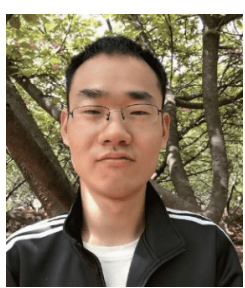

Pengsong $\mathbf{L i}$ is now a joint training $\mathrm{PhD}$ student at Beijing University of Chemical Technology (BUCT) in the group of Prof. Xiaoming Sun and Yale University working with Prof. Hailiang Wang. His current research interests include the synthesis of inorganic nanostructures and their application in energy conversion and storage.

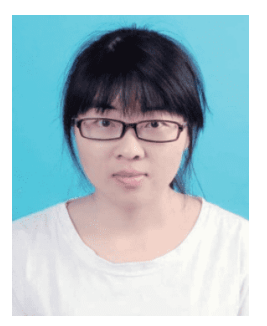

Xiuping Zhao is currently a graduate student at the State Key Laboratory of Chemical Resource Engineering, BUCT. Her research interests include the transition metal sulfide/hydroxide nanoarrays for electrocatalysis and DFT modeling studies.

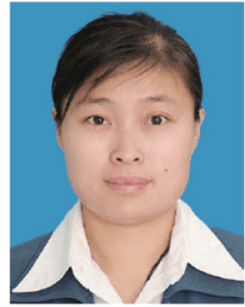

Yaping $\mathbf{L i}$ received her BSc degree from the Department of Chemical Engineering and $\mathrm{PhD}$ from the Department of Chemistry, Beijing Institute of Technology in 1996 and 2005, respectively. She joined the State Key Laboratory of Chemical Resource Engineering, BUCT at 2008. Her main research interests focus on the firstprinciple theory and density functional study on the OER mechanism for metal/metal oxides, and the corresponding nonlinear dynamics behaviors.

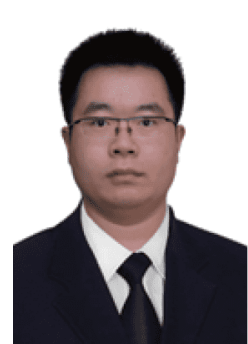

Yun Kuang obtained his $\mathrm{BE}$ and $\mathrm{PhD}$ degrees from BUCT in 2010 and 2015, respectively. He then joined the faculty of BUCT. He is now an associate professor in chemistry at the College of Chemistry, BUCT and a visiting associate professor in the Department of Chemistry at Stanford University. His current research interest mainly focuses on the synthesis, structure regulation and assembly of transitional metal based nanostructures under control, as well as their application in catalysis and energy related areas.

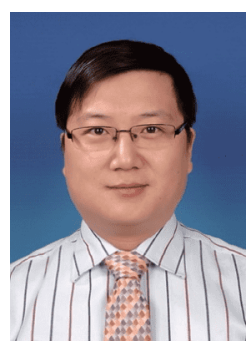

Xiaoming Sun obtained his $\mathrm{BSc}$ and $\mathrm{PhD}$ degrees at Tsinghua University in 2000 and 2005, respectively. He worked in Stanford University as a postdoc from 2005 to 2008. Then he joined BUCT and obtained the Foundation of Outstanding Young Scholar from NSFC in 2011. His current research interest mainly focuses on the synthesis and separation of nanomaterials, to improve the energy related electrocatalysis process by tailoring the compositions, surface wettability, and micro-/nano- structures.

\section{基于多相硫化镍铁的高效析氧电极材料}

李鹏松 ${ }^{\dagger}$, 赵秀萍 ${ }^{\dagger}$, 段欣璇, 李亚平 ${ }^{*}$, 广允 ${ }^{*}$, 孙晓明 ${ }^{*}$

摘要 开发高效和低成本的析氧电极材料是工业电解水制氢技术 发展道路上至关重要的技术难题. 本文利用溶剂热方法将镍铁水 滑石阵列转化为具有铁掺杂的多相硫化镍 $\left(\mathrm{NiS}^{2}\right.$ 和 $\left.\mathrm{Ni}_{3} \mathrm{~S}_{2}\right)$ 阵列, 制备 出一种具有高效析氧性能的电极材料. 粗粘的纳米片表面有利于 高活性位点的暴露. 电化学分析表明其仅需要 $100 \mathrm{mV}$ 的过电位就 可以达到 $10 \mathrm{~mA} \mathrm{~cm}^{-2}$ 的电流密度, 相对于镍铁水滑石阵列降低了 $130 \mathrm{mV}$. 我们进一步通过密度泛函理论计算来揭示其活性提升机 理, 发现具有部分 $\mathrm{S}$ 氧化的 $\mathrm{Fe}$ 掺杂 $\mathrm{NiS}$ 可以极大地降低析氧反应中 间体形成的阻力, 从而加快催化反应进行, 提高催化活性. 另一方 面, $(\mathrm{Ni}, \mathrm{Fe}) \mathrm{S}$ 和 $(\mathrm{Ni}, \mathrm{Fe})_{3} \mathrm{~S}_{2}$ 与三维多孔泡沫镍结构有很好的结合作用, 反应电子可以通过金属性的二硫化镍相进行高效传输, 进一步加 速析氧催化进程. 